\title{
Acervo fotográfico da Expedição Tapajós, Pará, Brasil
}

Realizada entre 05 e 07 de julho de 2018, a Expedição Tapajós teve o objetivo de explorar fotograficamente a margem do Rio Tapajós entre Alter do Chão (praia paradisíaca do Pará, Brasil) e a Floresta Nacional do Tapajós. A FLONA Tapajós foi criada em 1974 e desde então protege a biodiversidade do lugar. A região foi foco de intensa exploração da borracha, especialmente na cidade de Belterra, que em 1934 foi fundada por Henry Ford. O expedicionário Carlos Eduardo Silva (Cadu Silva) iniciou os trabalhos na tarde de 05 de julho de 2018, com o reconhecimento da praia de Alter do Chão, contatos logísticos, e uma trilha até a Serra da Piraoca. 0 dia 06 de julho iniciou com o trajeto fotográfico da Praia do Cajueiro (Alter do Chão) pela margem esquerda de subida do Rio Tapajós até a Comunidade de Jamaraquá na FLONA Tapajós, em trajeto de $38 \mathrm{~km}$ de barco com duração de 3,5h ida e 3,5h volta. Na Comunidade Jamaraquá foi possível apreciar o contato com turistas de outras países, culinária local e trilhas pela floresta, com especial destaque para a gigantesca árvore chamada Vovózona. 0 dia 07 de julho fo utilizado para tratamento das fotografias, e logística de retorno até Aracaju (SE).

Palavras-chave: Expedição; Fotografia; Rio Tapajós; Floresta Nacional do Tapajós; Comunidade Jamaraquá.

\section{Tapajós Expedition Photographic Collection, Pará, Brazil}

Held between July 5 and July 7, 2018, the Tapajós Expedition aimed to photographically explore the Tapajós riverbank between Alter do Chão (Pará's paradise beach, Brazil) and the Tapajós National Forest. FLONA Tapajós was created in 1974 and since then protects the biodiversity of the place. The region was the focus of intense rubber exploitation, especially in the city of Belterra, which in 1934 was founded by Henry Ford. Expeditionary Carlos Eduardo Silva (Cadu Silva) began work on the afternoon of July 5, 2018, with the recognition of Alter do Chão beach, logistical contacts, and a trail to Serra da Piraoca. July 6th began with the photographic journey from Cajueiro Beach (Alter do Chão) along the left rising bank of the Tapajós River to the Community of Jamaraquá at FLONA Tapajós, in a $38 \mathrm{~km}$ long boat trip $(3,5 \mathrm{~h})$ and 3.5 hours back. In Jamaraquá Community it was possible to enjoy the contact with tourists from other countries, local cuisine and trails through the forest, with special emphasis on the giant tree called Vovózona. July 7th was used for photo processing and return logistics to Aracaju (SE).

Keywords: Expedition; Photography; Tapajós River; Tapajós National Forest; Jamaraquá Community.

Topic: Registro de Obras Artísticas

Reviewed anonymously in the process of blind peer.
Received: 10/05/2019

Approved: 10/05/2019
Carlos Eduardo Silva (iD)

Companhia Brasileira de Produção Científica, Brasil

http://lattes.cnpq.br/3700554054159220

http:///orcid.org/0000-0001-8358-0263

carlos.eduardo@cbpciencia.com.br
Referencing this:

SILVA, C. E.. Acervo fotográfico da Expedição Tapajós, Pará, Brasil. Social Evolution, v.3, n.1, p.3-14, 2019. DOI:

http://doi.org/10.6008/CBPC2595-430X.2019.001.0002

DOI: 10.6008/CBPC2595-430X.2019.001.0002 


\section{OBRA}

Fotografia 001: Construções flutuantes no istmo inundado de inverno em Alter do Chão, Pará, Brasil.

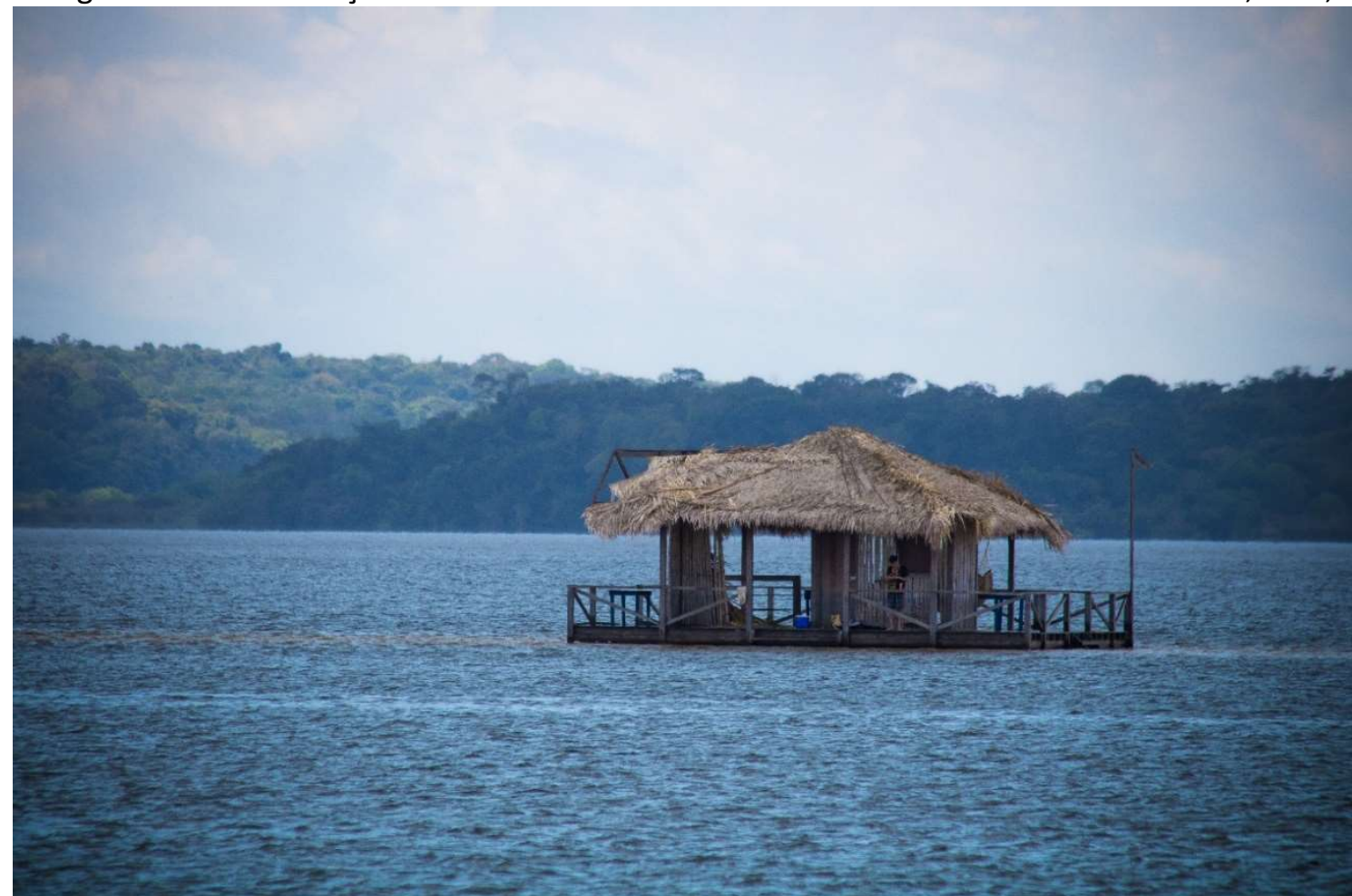

Data: 05/07/2018, 13:21h; Câmera: Canon EOS Rebel T6i; Abertura: f/8; Exposição: 1/400s; ISO 200; Distância Focal: $300 \mathrm{~mm}$.

Fotografia 002: Paisagem vista do alto da Serra de Piraoca, Alter do Chão, Pará, Brasil.

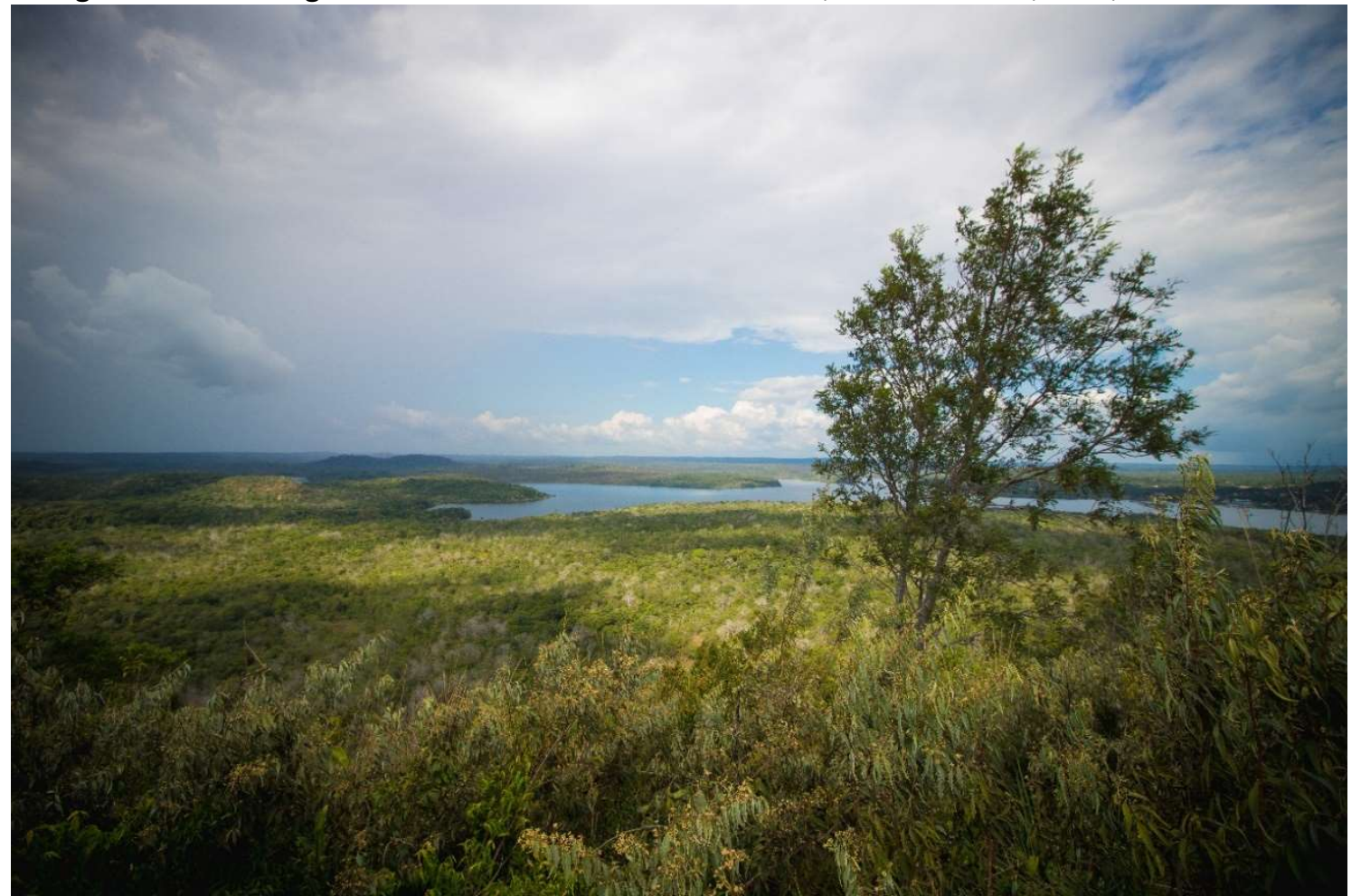

Data: 05/07/2018, 15:08h; Câmera: Canon EOS Rebel T6i; Abertura: f/8; Exposição: 1/250s; ISO 100; Distância Focal: $10 \mathrm{~mm}$. 
Fotografia 003: Banco existente no topo da Serra da Piraoca, com dizer "Limits do not exist".

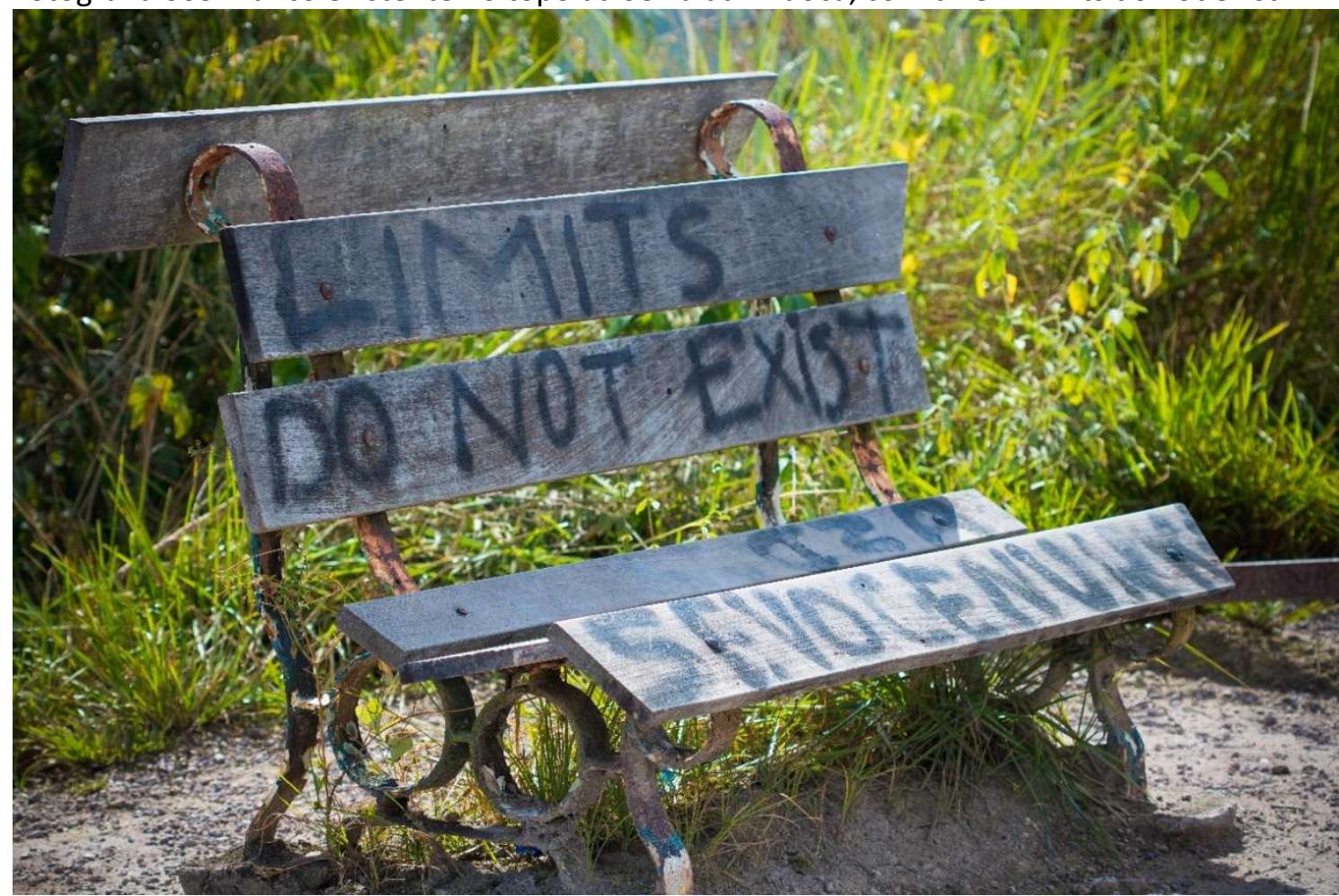

Data: 05/07/2018, 15:15h; Câmera: Canon EOS Rebel T6i; Abertura: f/5; Exposição: 1/400s; ISO 100; Distância Focal: 100mm.

Fotografia 004: Armadilha de aranhas para insetos na trilha da Serra da Piraoca.

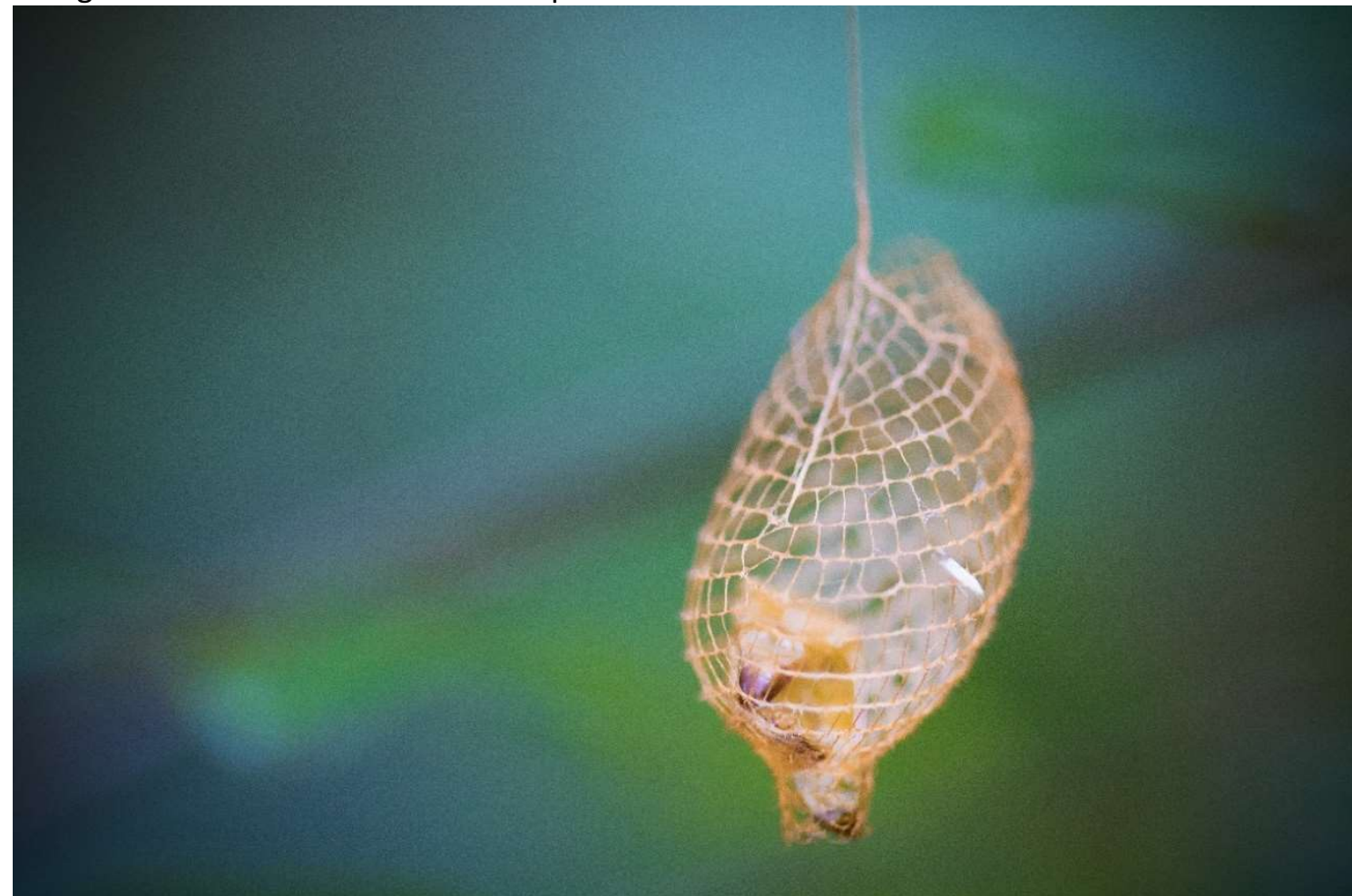

Data: 05/07/2018, 15:32h; Câmera: Canon EOS Rebel T6i; Abertura: f/2.8; Exposição: 1/125s; ISO 800; Distância Focal: $100 \mathrm{~mm}$. 
Fotografia 005: Gafanhoto da Serra da Piraoca.

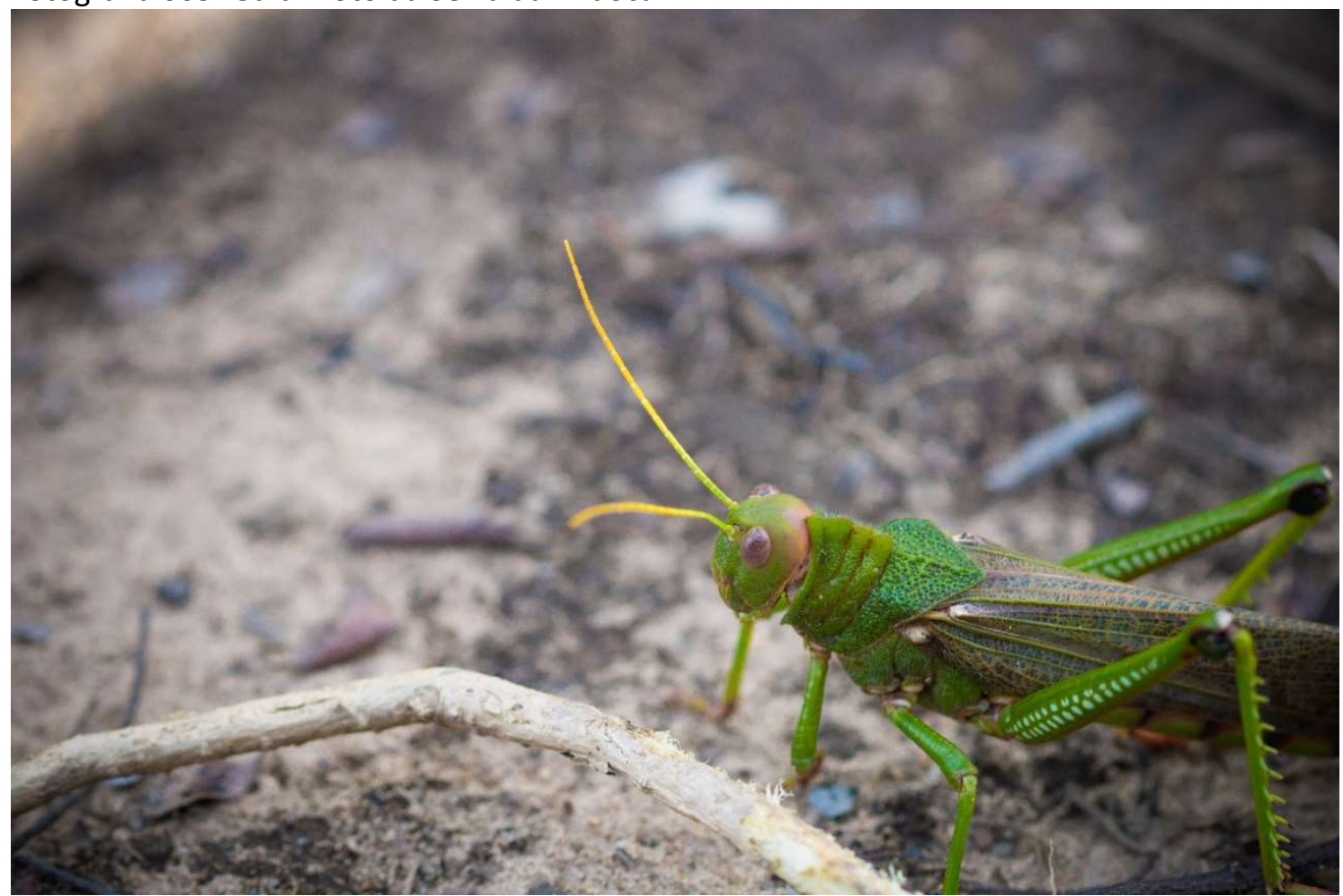

Data: 05/07/2018, 15:52h; Câmera: Canon EOS Rebel T6i; Abertura: f/3.2; Exposição: 1/160s; ISO 100; Distância Focal: 100mm.

Fotografia 006: Iguana na Praia do Cajueiro, Alter do Chão, Pará, Brasil.

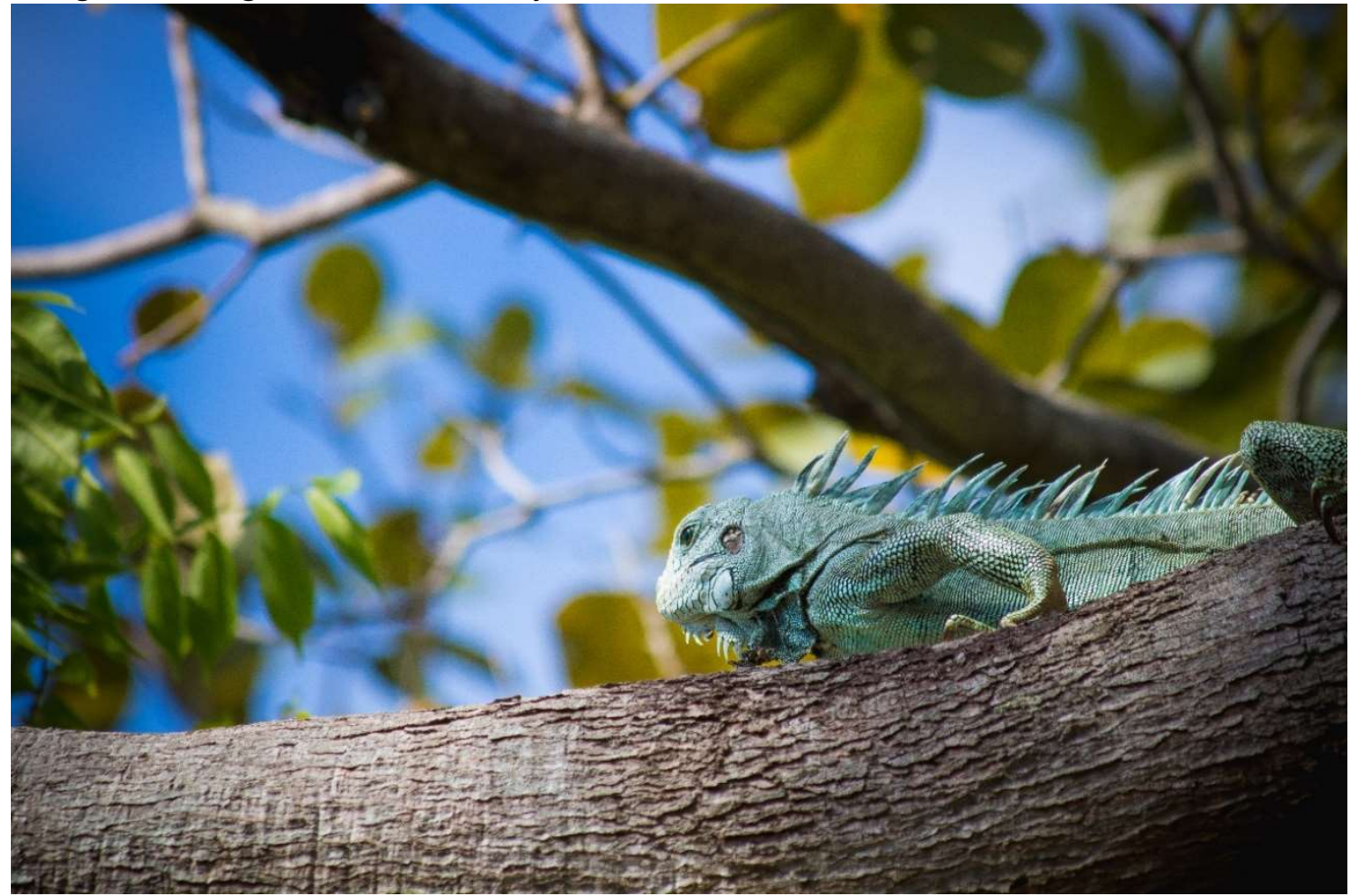

Data: 05/07/2018, 16:14h; Câmera: Canon EOS Rebel T6i; Abertura: f/5.6; Exposição: 1/400s; ISO 250; Distância Focal: 300mm. 
Fotografia 007: Iguana na Praia do Cajueiro, Alter do Chão, Pará, Brasil.

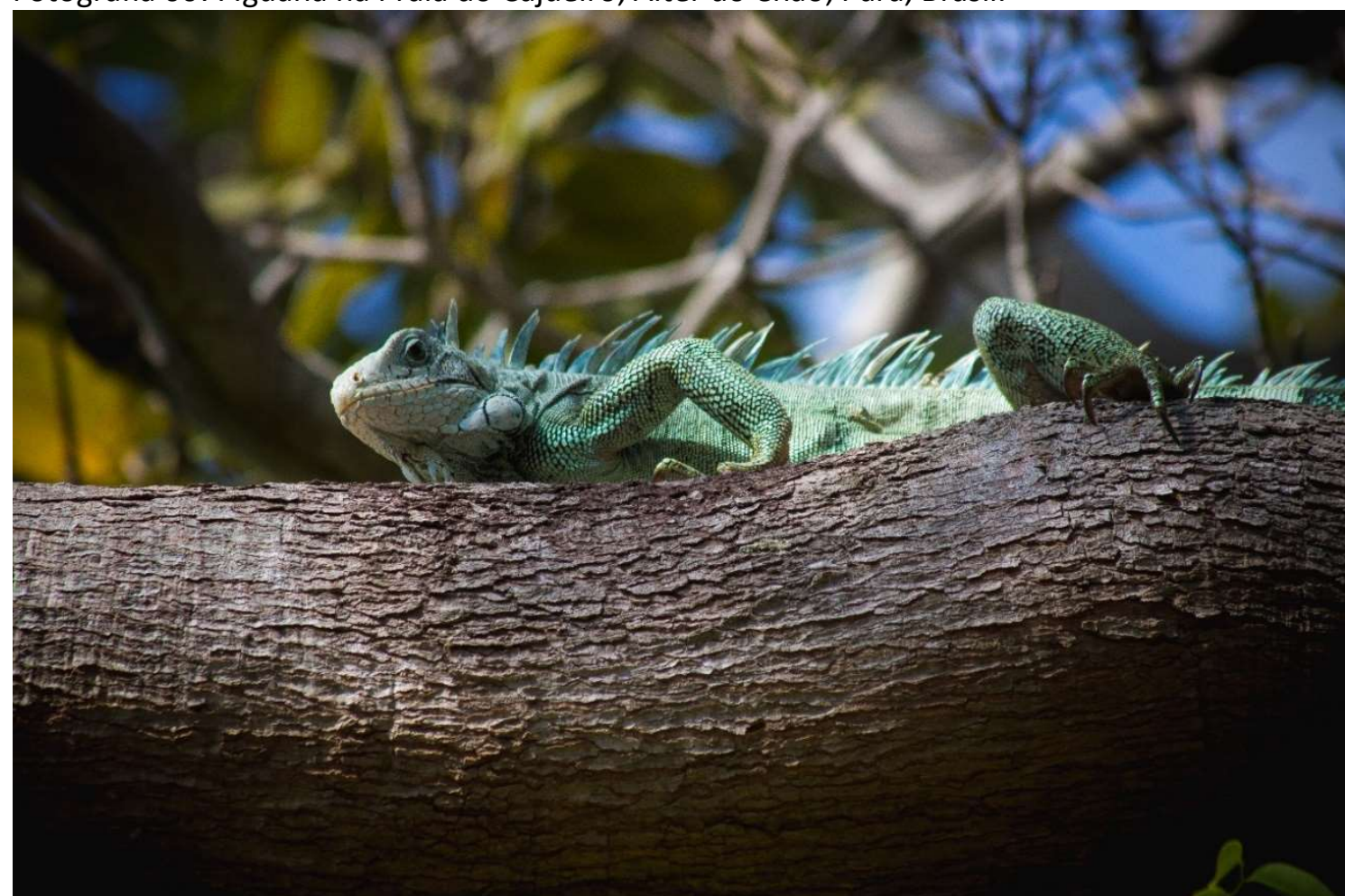

Data: 05/07/2018, 16:14h; Câmera: Canon EOS Rebel T6i; Abertura: f/6.3; Exposição: 1/400s; ISO 250; Distância Focal: 300mm.

Fotografia 008: Pássaros nas praias ribeirinhas do Rio Tapajós, Pará, Brasil.

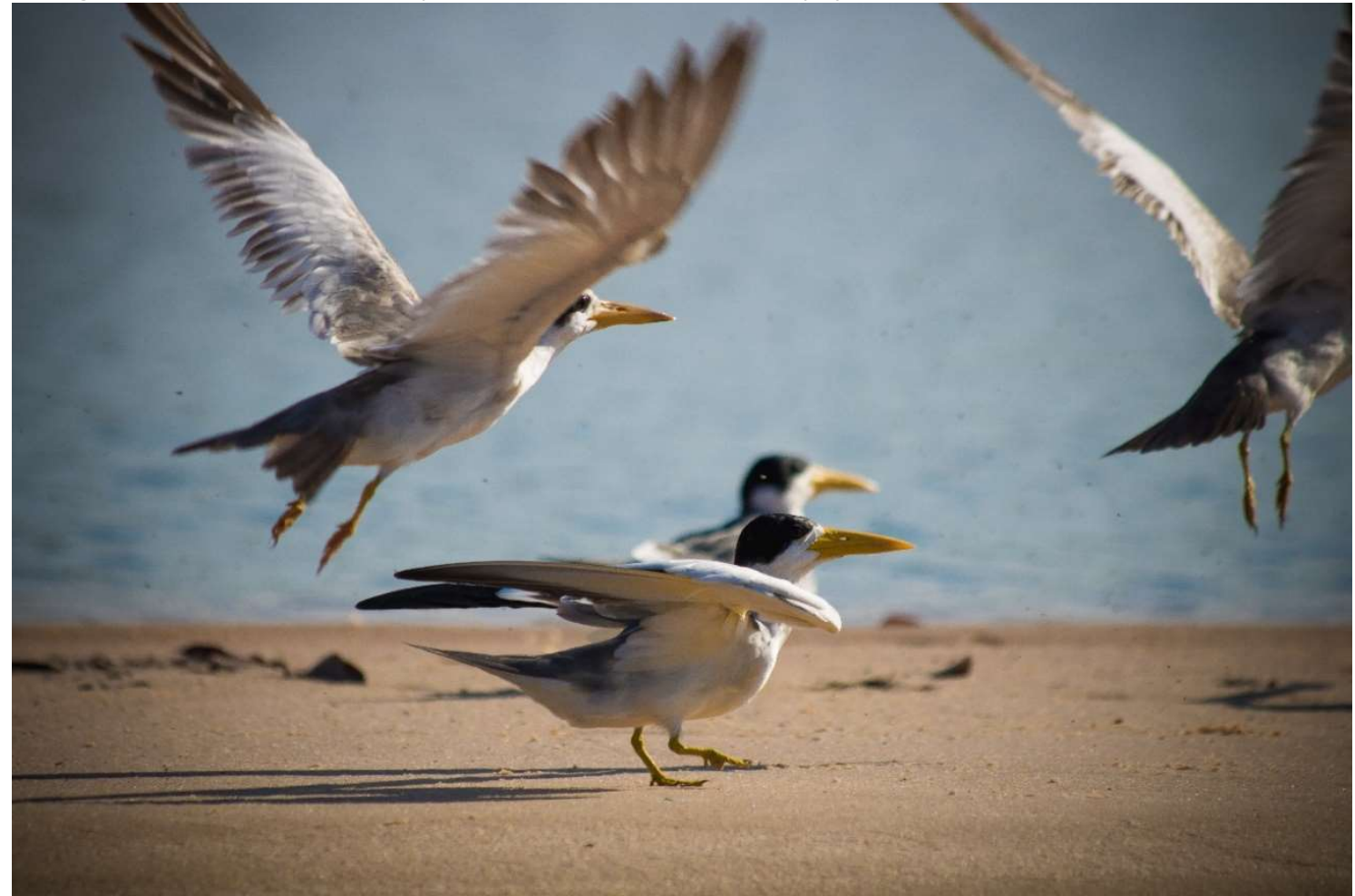

Data: 06/07/2018, 08:50h; Câmera: Canon EOS Rebel T6i; Abertura: f/5.6; Exposição: 1/800s; ISO 100; Distância Focal: 300mm. 
Fotografia 009: Ruínas às margens do Rio Tapajós, Belterra, Pará, Brasil.

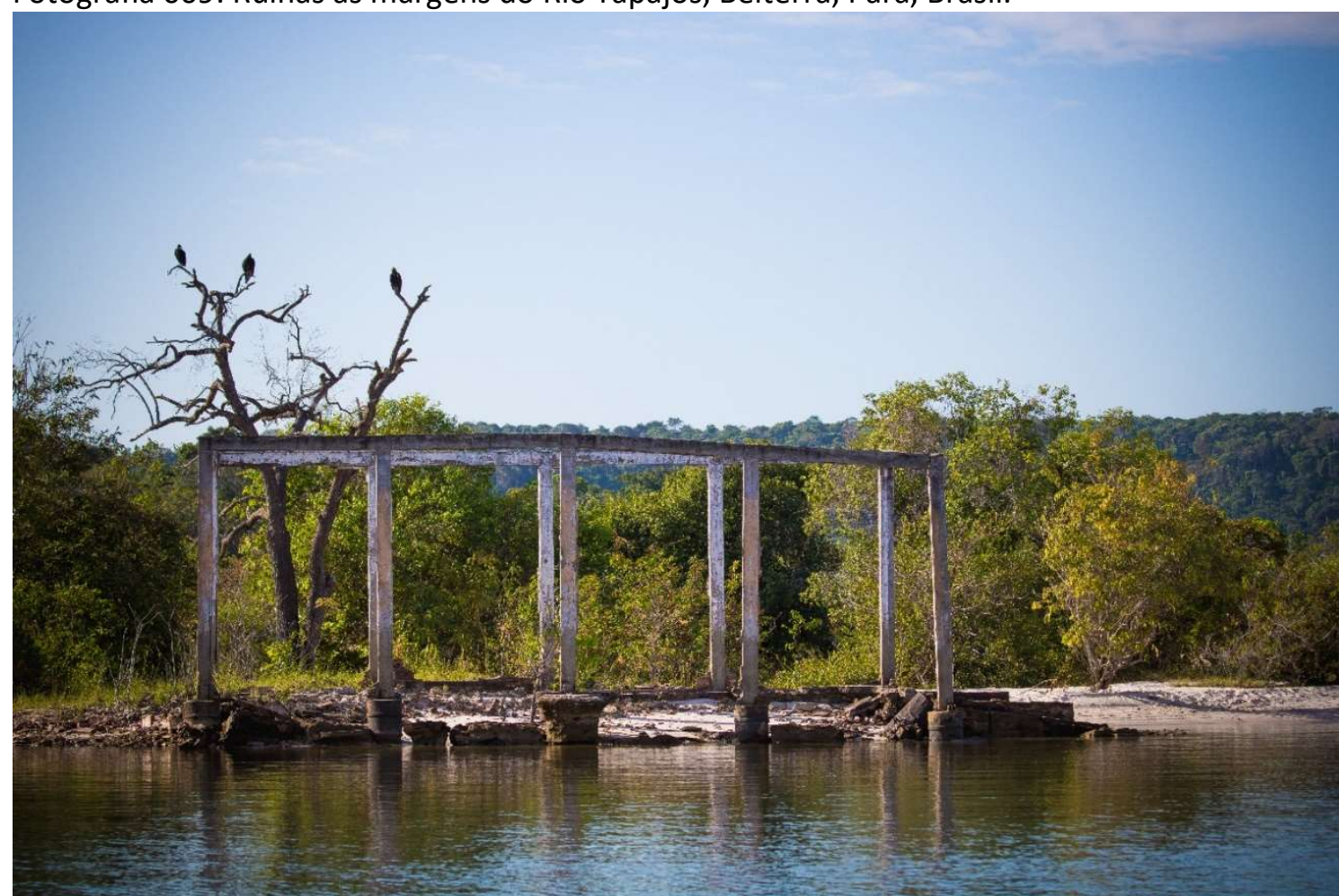

Data: 06/07/2018, 08:52h; Câmera: Canon EOS Rebel T6i; Abertura: f/5.6; Exposição: 1/320s; ISO 100; Distância Focal: $70 \mathrm{~mm}$.

Fotografia 010: Praias do Rio Tapajós, Belterra, Pará, Brasil.

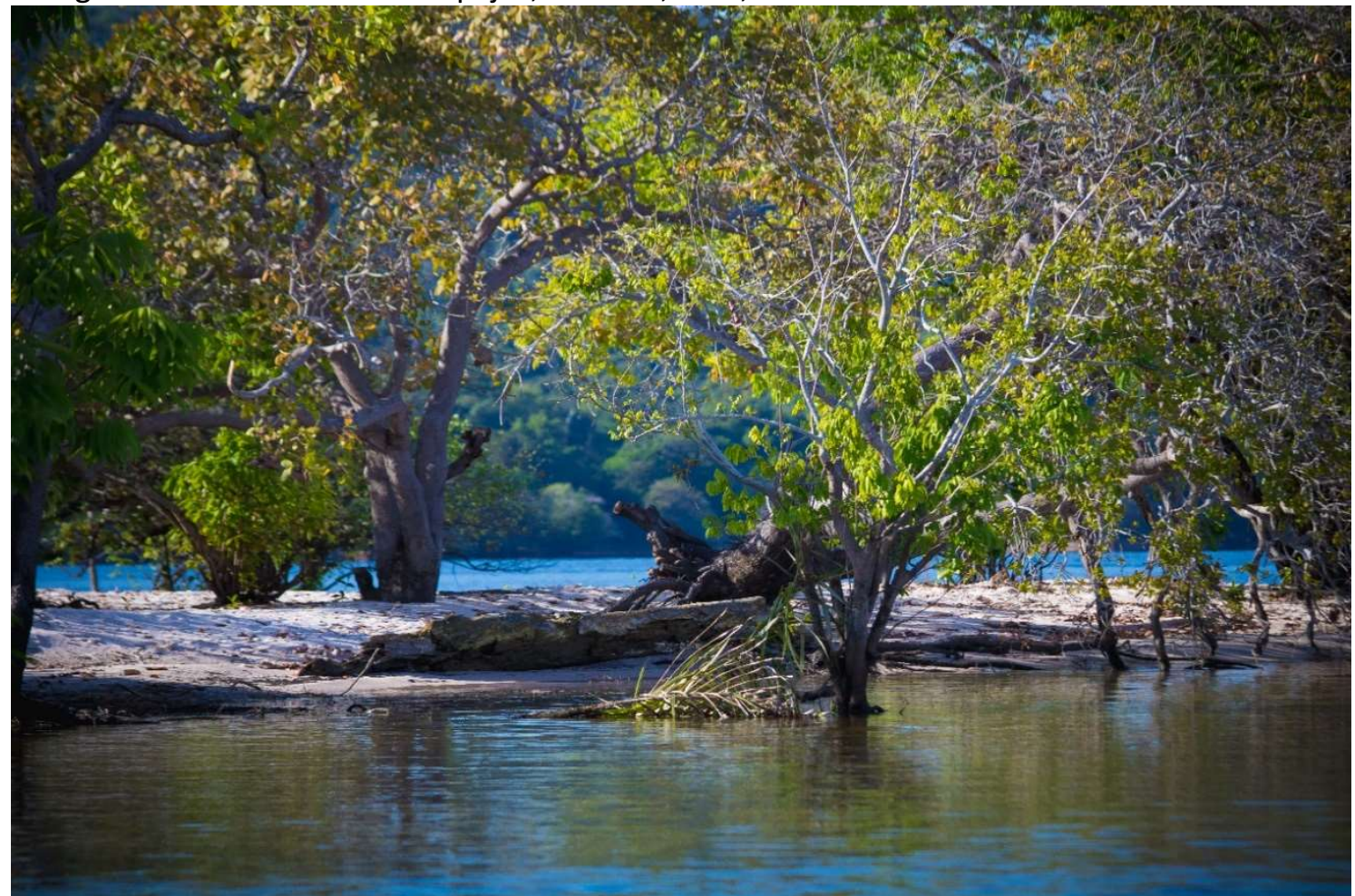

Data: 06/07/2018, 08:52h; Câmera: Canon EOS Rebel T6i; Abertura: f/5.6; Exposição: 1/250s; ISO 100; Distância Focal: $160 \mathrm{~mm}$. 
Fotografia 011: Praias do Rio Tapajós, Belterra, Pará, Brasil.

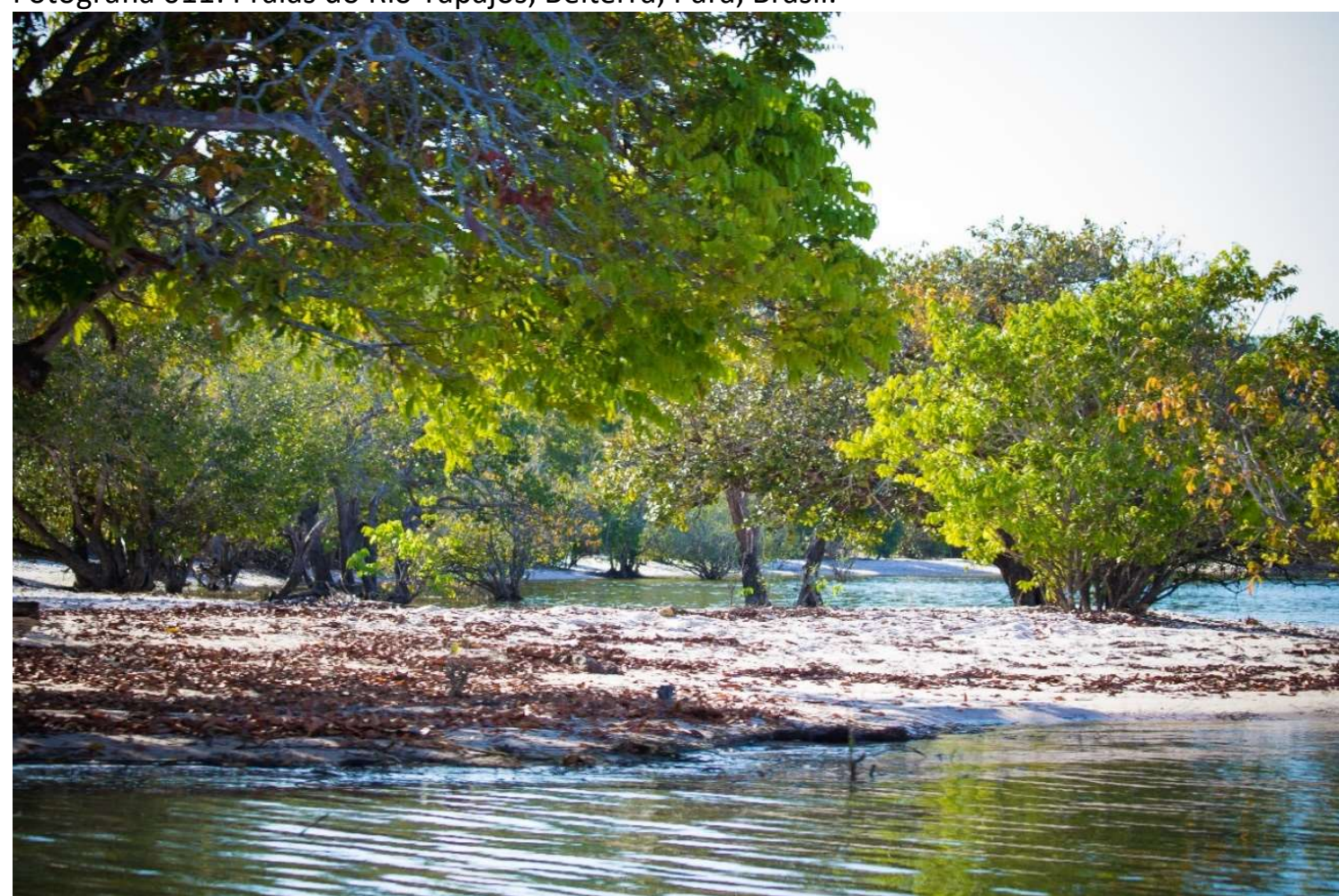

Data: 06/07/2018, 08:53h; Câmera: Canon EOS Rebel T6i; Abertura: f/5.6; Exposição: 1/160s; ISO 100; Distância Focal: $75 \mathrm{~mm}$.

Fotografia 012: Pássaro em troncos inundados no Rio Tapajós, Pará.

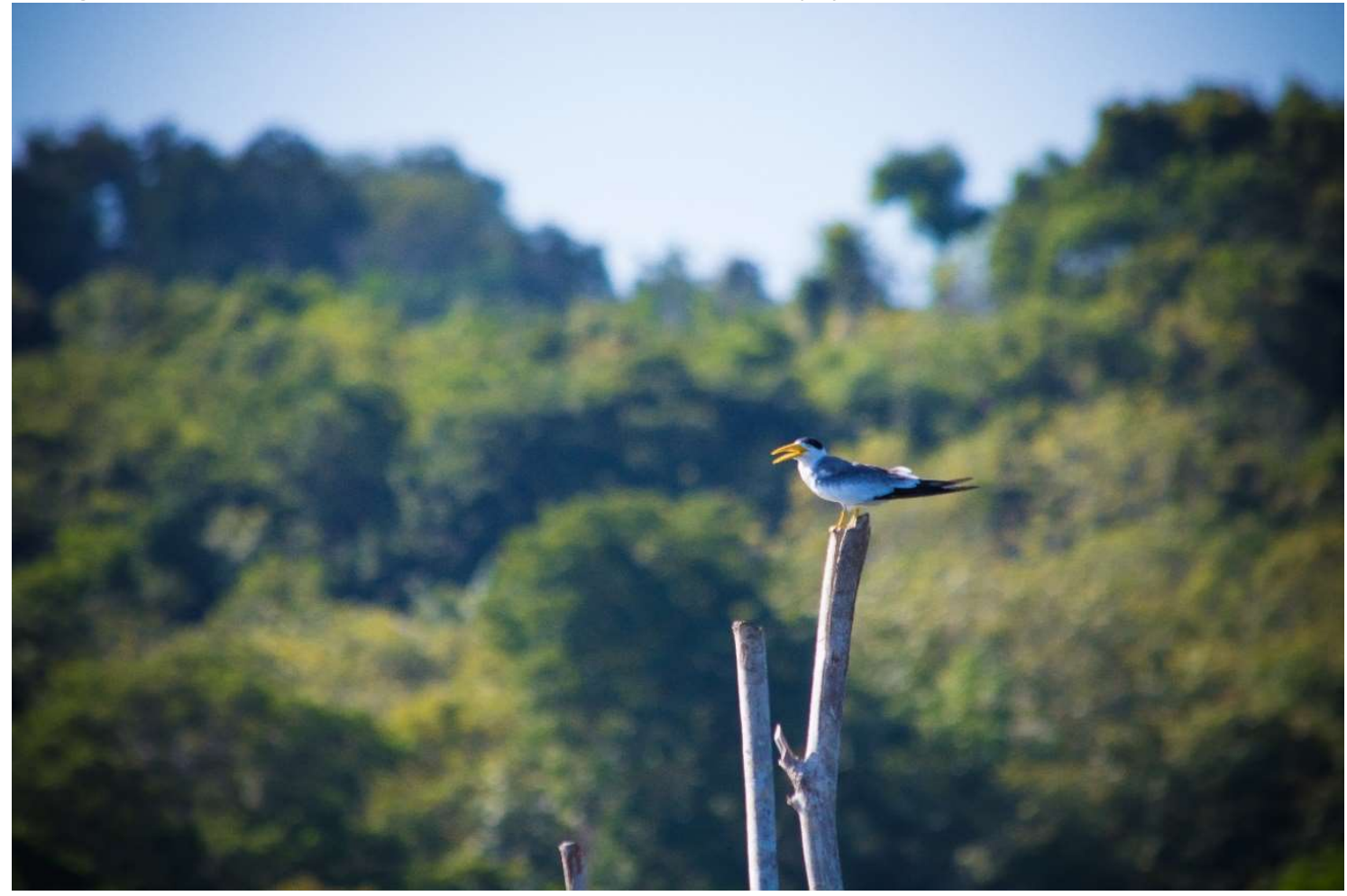

Data: 06/07/2018, 09:49h; Câmera: Canon EOS Rebel T6i; Abertura: f/6.3; Exposição: 1/400s; ISO 200; Distância Focal: $300 \mathrm{~mm}$. 
Fotografia 013: Árvore inundada no Rio Tapajós, Belterra, Pará, Brasil.

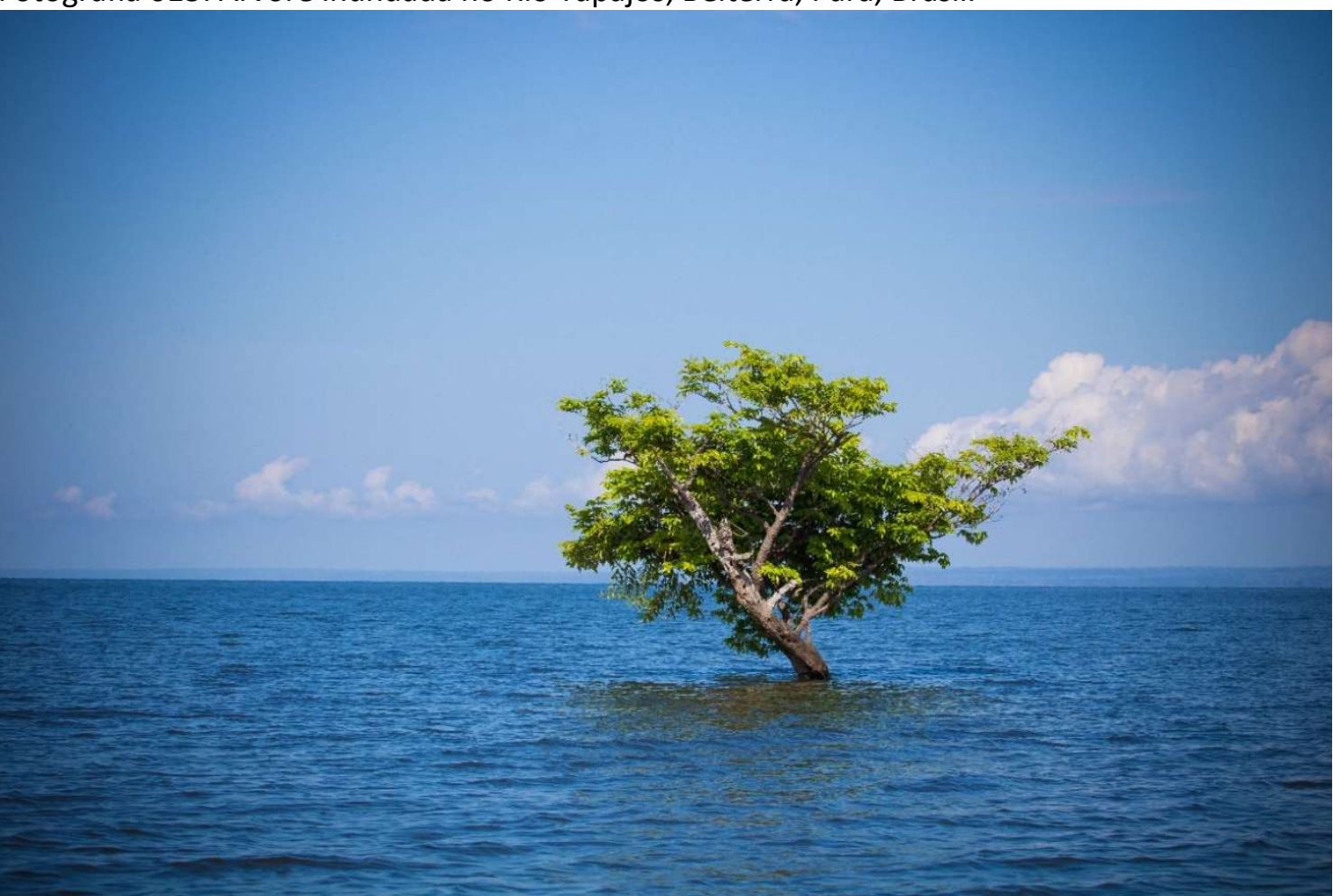

Data: 06/07/2018, 10:03h; Câmera: Canon EOS Rebel T6i; Abertura: f/7.1; Exposição: 1/400s; ISO 100; Distância Focal: $70 \mathrm{~mm}$.

Fotografia 014: Casa tradicional da comunidade Jamaraquá, Floresta Nacional do Tapajós, Pará, Brasil.

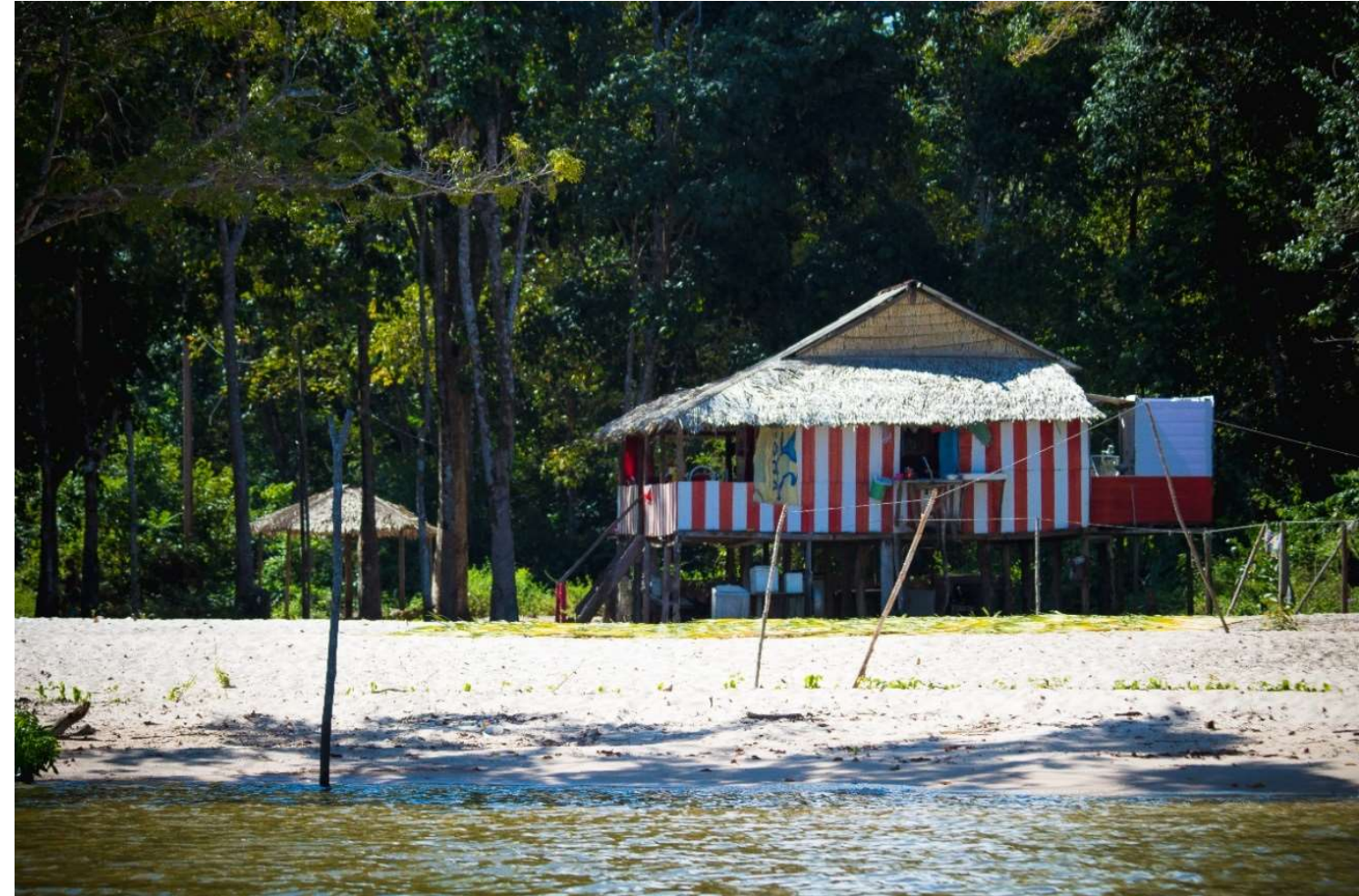

Data: 06/07/2018, 10:27h; Câmera: Canon EOS Rebel T6i; Abertura: f/5.6; Exposição: 1/250s; ISO 100; Distância Focal: $100 \mathrm{~mm}$. 
Fotografia 015: Guia Donilson explicando a extração da borracha na Seringueira, trilha da Comunidade Jamaraquá, FLONA Tapajós, Pará, Brasil.

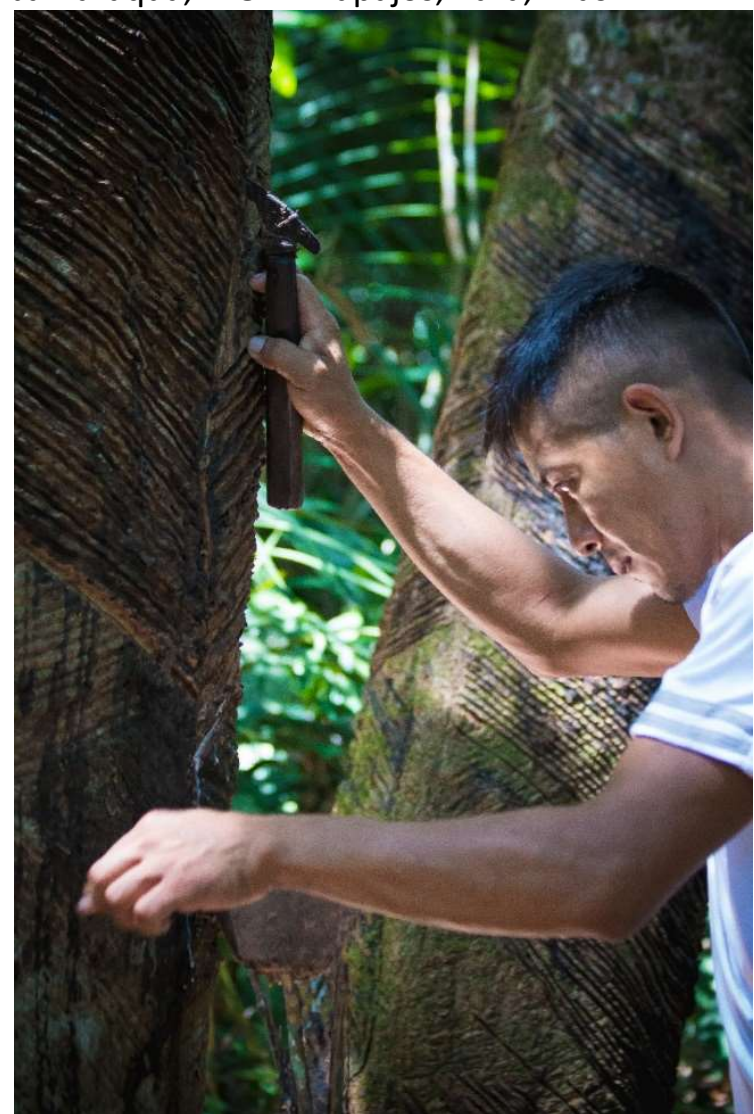

Data: 06/07/2018, 12:13h; Câmera: Canon EOS Rebel T6i; Abertura: f/4.5; Exposição: 1/100s; ISO 1000; Distância Focal: $75 \mathrm{~mm}$.

Fotografia 016: Teto da Floresta Nacional do Tapajós, Pará, Brasil.

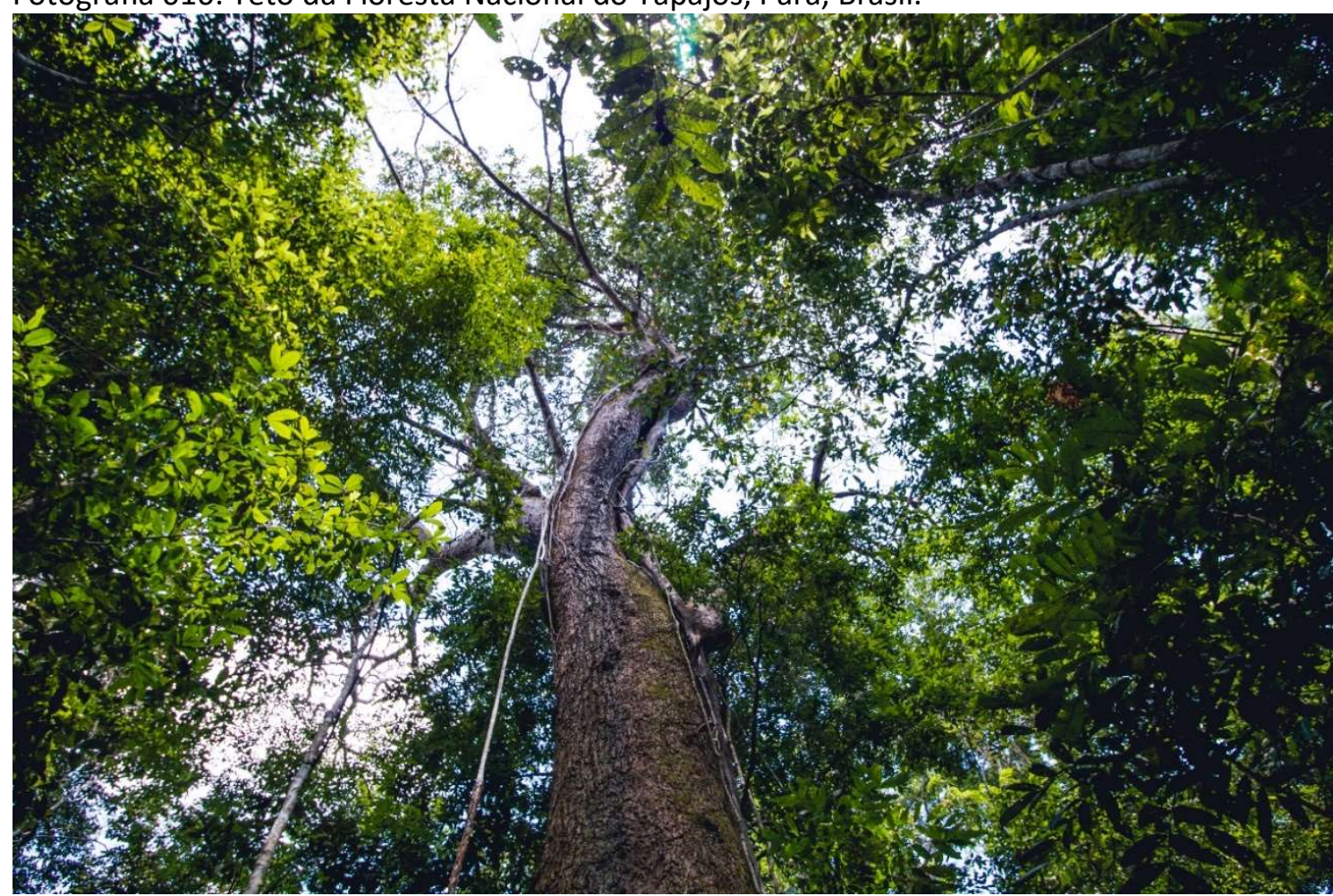

Data: 06/07/2018, 12:52h; Câmera: Canon EOS Rebel T6i; Abertura: f/6.3; Exposição: 1/50s; ISO 100; Distância Focal: 13mm. 
Fotografia 017: Tronco de árvore na Floresta Nacional do Tapajós, Pará, Brasil.

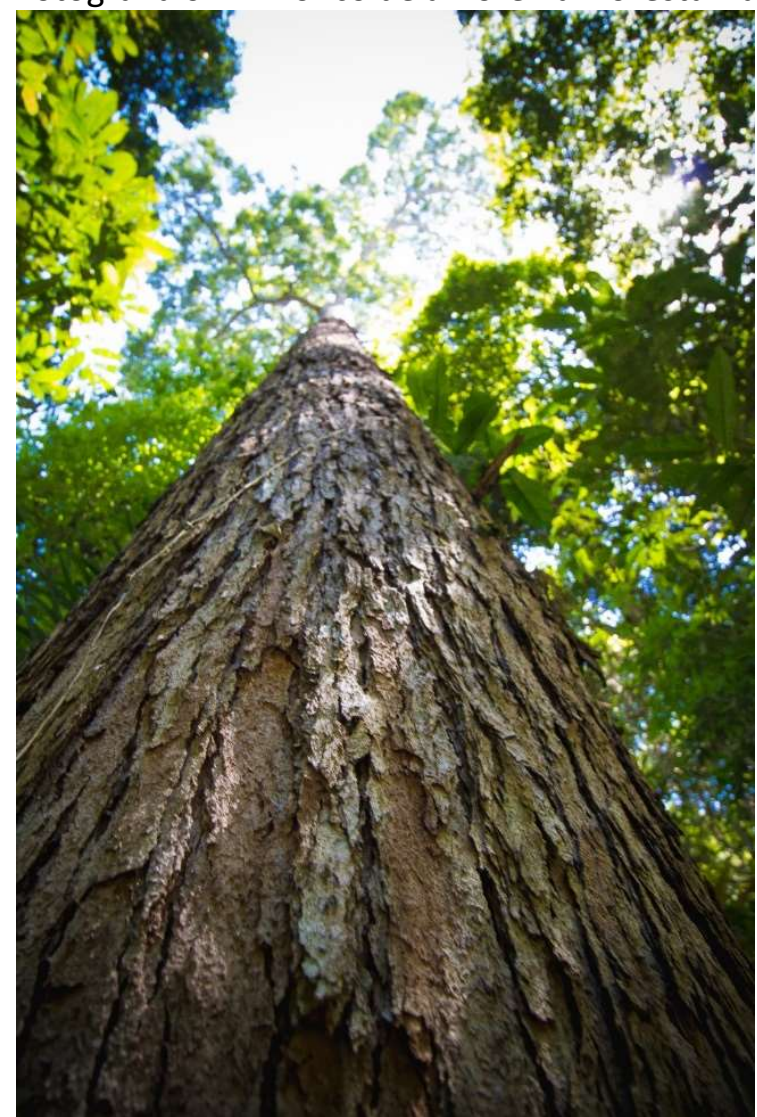

Data: 06/07/2018, 12:57h; Câmera: Canon EOS Rebel T6i; Abertura: f/5; Exposição: 1/30s; ISO 160; Distância Focal: $13 \mathrm{~mm}$.

Fotografia 018: Gigantesca Sumaúma apelidada carinhosamente de vovózona, junto ao expedicionário Cadu Silva.

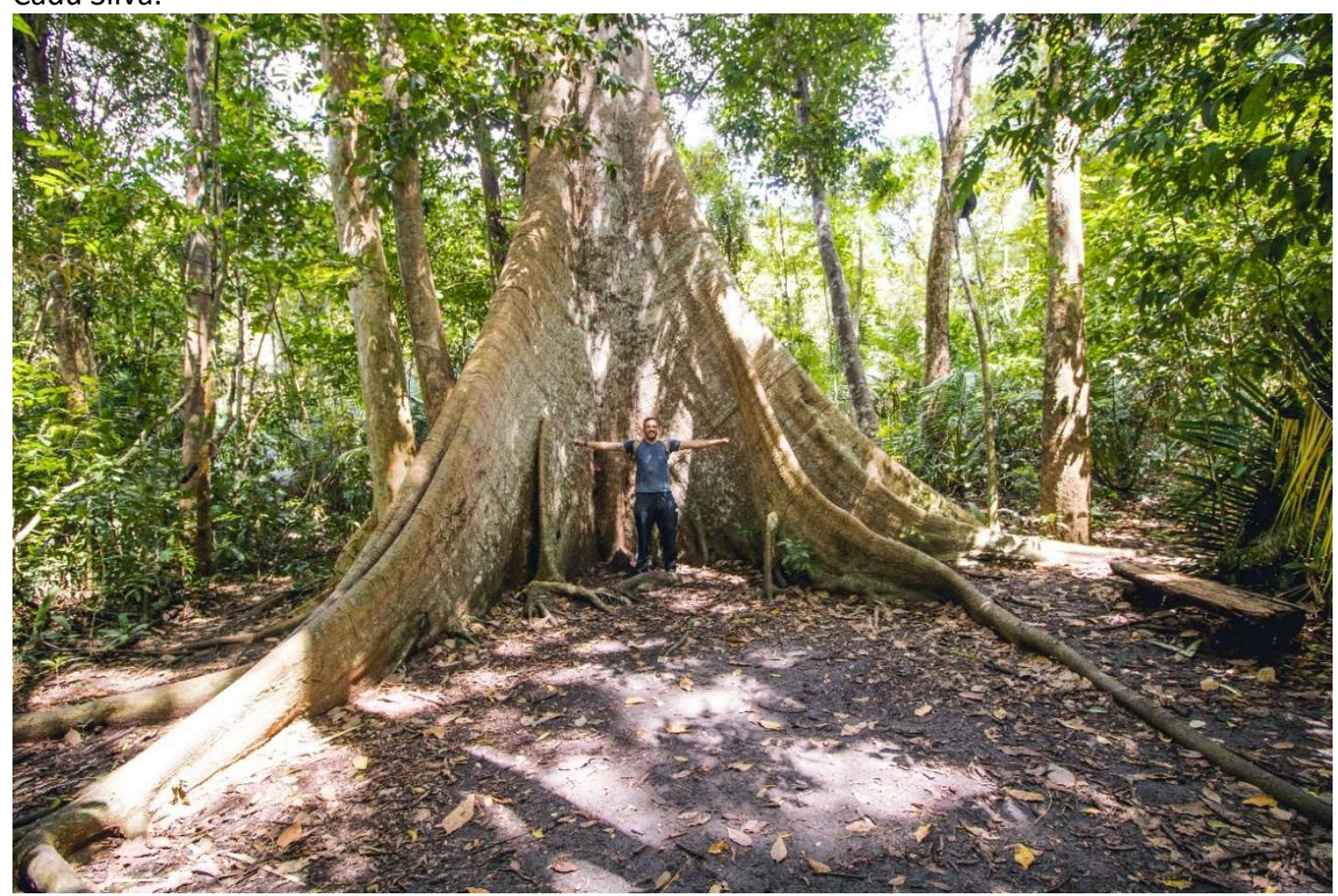

Data: 06/07/2018, 13:34h; Câmera: Canon EOS Rebel T6i; Abertura: f/5; Exposição: 1/30s; ISO 250; Distância Focal: 10mm. Foto: Donilson Jamaraquá. 
Fotografia 019: Rio Tapajós visto do ponto mais alto da trilha da Comunidade Jamaraquá, Floresta Nacional do Tapajós, Pará, Brasil.

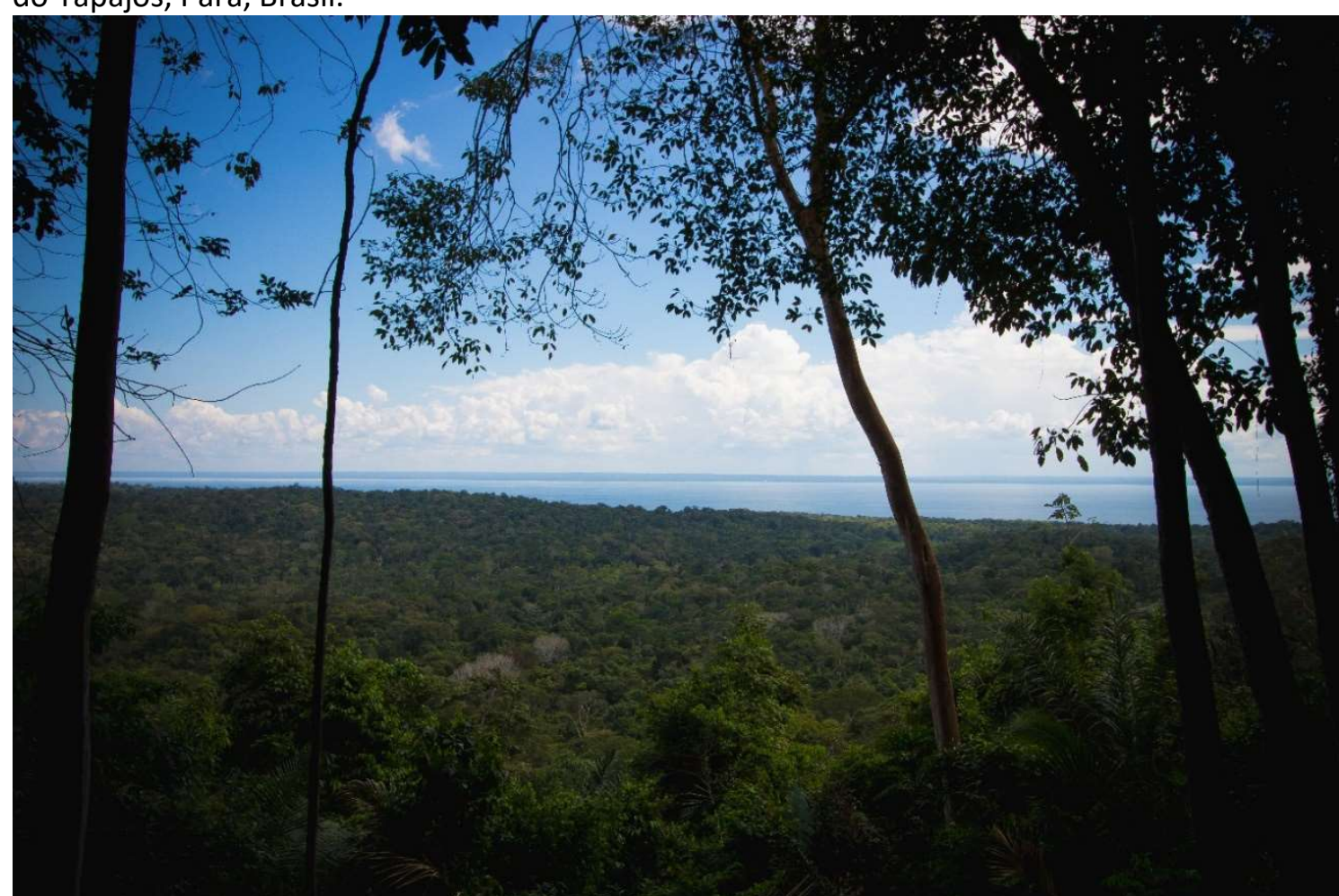

Data: 06/07/2018, 13:46h; Câmera: Canon EOS Rebel T6i; Abertura: f/11; Exposição: 1/125s; ISO 100; Distância Focal: 18mm.

Fotografia 020: Inseto popularmente conhecido como Soldado, trilha da Comunidade Jamaraquá, FLONA Tapajós, Pará, Brasil.

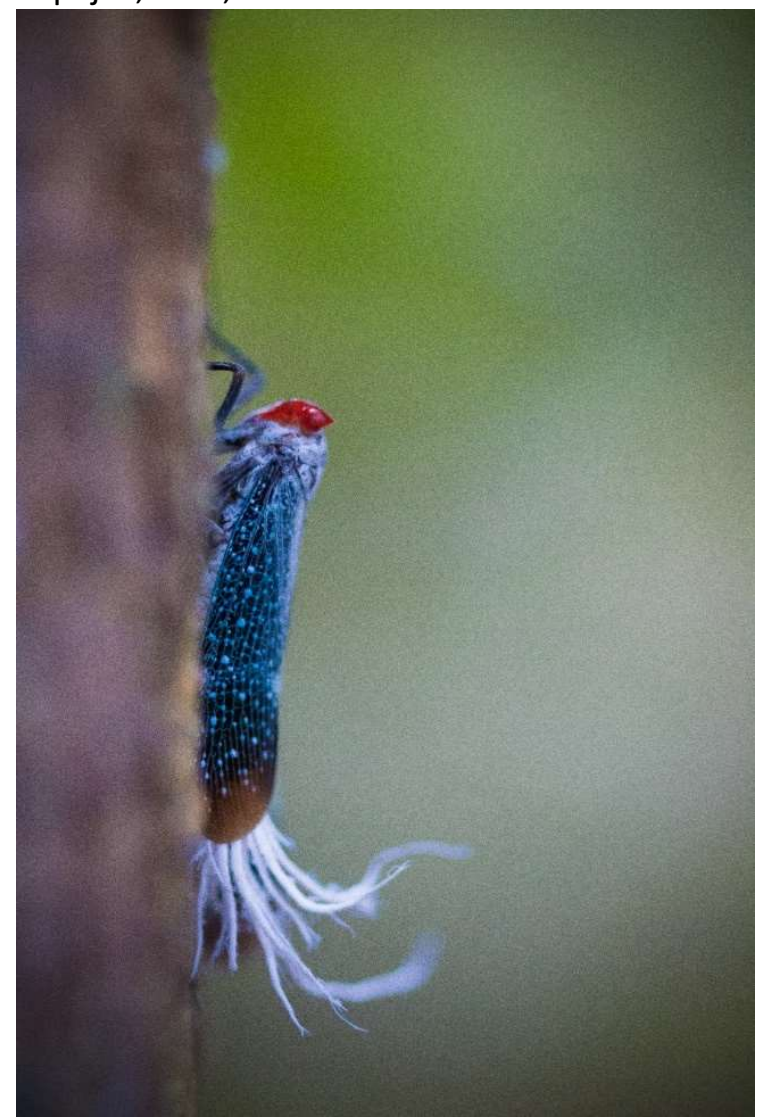

Data: 06/07/2018, 14:31h; Câmera: Canon EOS Rebel T6i; Abertura: f/2.8; Exposição: 1/125s; ISO 3200; Distância Focal: 100mm. 
Fotografia 021: Selfie do expedicionário e fotógrafo Cadu Silva, ao fundo embarcação comandada pelo guia Leonardo, e ruínas de uma tarde chuvosa no Rio Tapajós.

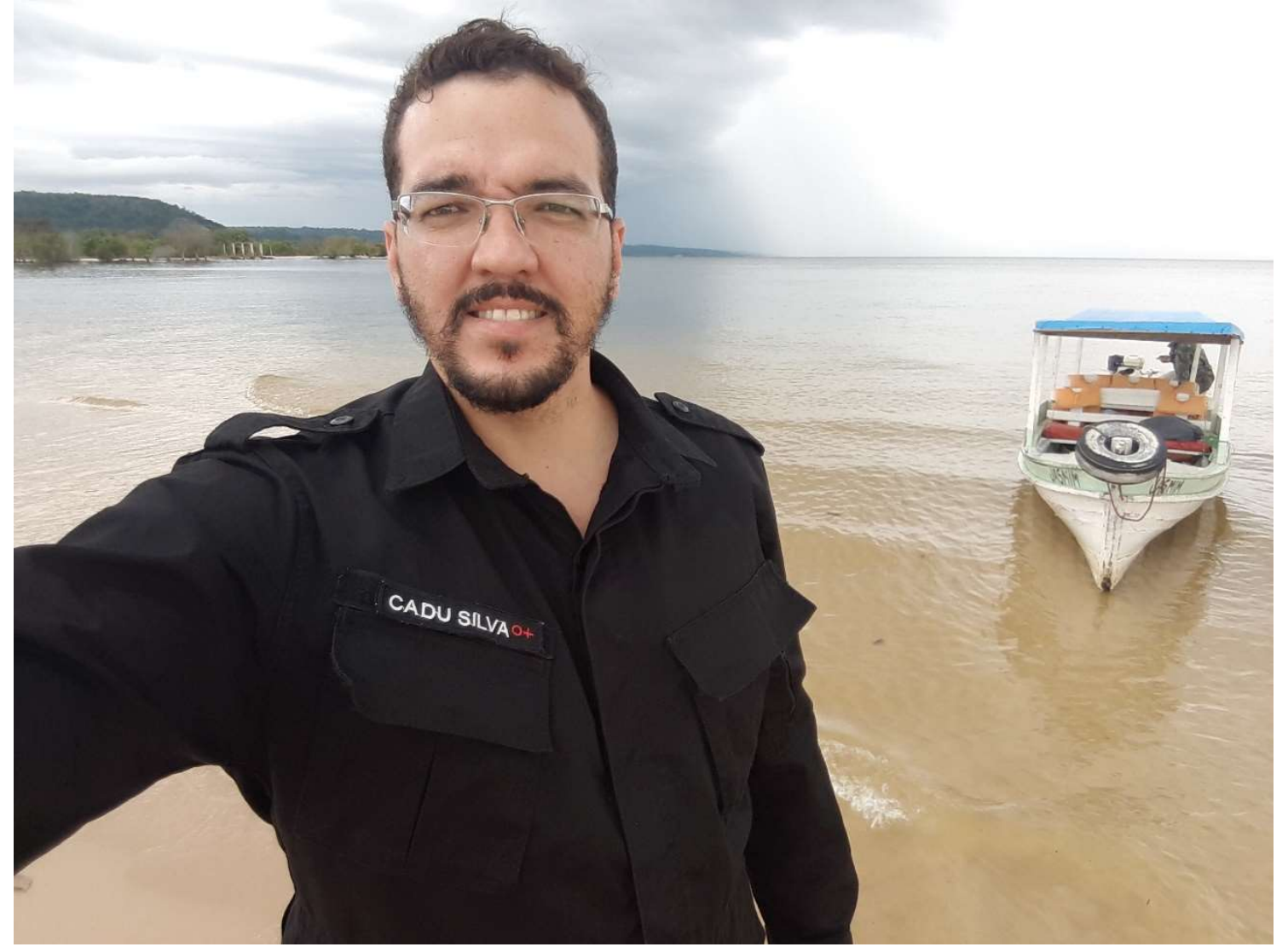

Data: 06/07/2018, 16:40h; Câmera: Samsung SM-A510M; Abertura: f/1.9; Exposição: 1/197s; ISO 50; Distância Focal: $2 \mathrm{~mm}$.

AGRADECIMENTOS: à Universidade Federal do Oeste do Pará (UFOPA), pelo convite para ministrar palestra aos seus alunos e pela oportunidade de conhecer este maravilhoso lugar. Ao guia Leonardo que conduziu a trilha até a Serra da Piraoca e as etapas de barco pelo Rio Tapajós. Ao guia Donilson que conduziu a trilha pela Floresta Nacional do Tapajós. Aos colaboradores da Pousada Hostel Tapajós pela excelente estada.

A CBPC - Companhia Brasileira de Produção Científica (CNPJ: 11.221.422/0001-03) detém os direitos materiais desta publicação. Os direitos referem-se à publicação do trabalho em qualquer parte do mundo, incluindo os direitos às renovações, expansões e disseminações da contribuição, bem como outros direitos subsidiários. Todos os trabalhos publicados eletronicamente poderão posteriormente ser publicados em coletâneas impressas sob coordenação da Sustenere Publishing, da Companhia Brasileira de Produção Científica e seus parceiros autorizados. Os (as) autores (as) preservam os direitos autorais, mas não têm permissão para a publicação da contribuição em outro meio, impresso ou digital, em português ou em tradução. Em exceção, os autores da seção especial "Registro de Obras Artísticas (fotografias, músicas, poesias, poemas, sonetos etc.)", existente em periódicos da área "Artes/Música”, preservam os direitos autorais e materiais. 